\title{
Avaliação de fontes e de extratores de silício no solo
}

\author{
Hamilton Seron Pereira(1), Newton Cabral Barbosa ${ }^{(1)}$, Marco Aurélio Carbone Carneiro(1) $^{(1)}$ \\ e Gaspar Henrique Korndörfer(2)
}

\begin{abstract}
(1)Universidade Federal de Goiás, Campus de Jataí, Centro de Ciências Agrárias e Biológicas, Rod. BR 364, Km 192, Zona Rural, CEP75800-000 Jataí, GO. E-mail: hsp@jatai.ufg.br, cabralagro@gmail.com, carbonecarneiro@yahoo.com.br (2)Universidade Federal de Uberlândia, Instituto de Ciências Agrárias, Caixa Postal 593, CEP 38400-902 Uberlândia, MG. E-mail: ghkorndorfer@terra.com.br
\end{abstract}

Resumo - O objetivo deste trabalho foi avaliar extratores e fontes de silício ( $\mathrm{Si}$ ) na cultura do arroz em Neossolo Quartzarênico em casa de vegetação. O delineamento experimental foi feito em esquema fatorial (26x7) inteiramente casualizado com 25 fontes de silício, aplicadas à dose de $250 \mathrm{~kg} \mathrm{ha}^{-1} \mathrm{de} \mathrm{Si} \mathrm{e} \mathrm{a} \mathrm{testemunha,} \mathrm{e} 7$ extratores de Si no solo. Tratamentos adicionais com 125, 375 e $500 \mathrm{~kg} \mathrm{ha}^{-1} \mathrm{de} \mathrm{Si} \mathrm{foram} \mathrm{aplicados} \mathrm{com} \mathrm{wollastonita.} \mathrm{Depois}$ de 90 dias do plantio, foi avaliada a produção de matéria seca da parte aérea e os teores de Si no solo e na planta. A fonte que proporcionou maior teor de Si às plantas de arroz foi sílica gel, e a pior fonte foi a MB-4. Os extratores apresentaram aumento linear do teor de Si no solo com o incremento das doses de wollastonita. Entre os tratamentos, a maior extração de Si ocorreu com o ácido acético; o cloreto de cálcio foi o extrator com a melhor correlação. $\mathrm{O}$ carbonato de amônio e o acetato de amônio, além de apresentarem correlações próximas às do cloreto de cálcio, tiveram ainda uma melhor distribuição dos pontos, o que discriminou melhor as variações entre as diferentes fontes de $\mathrm{Si}$.

Termos para indexação: Oryza sativa, escórias, agregado siderúrgico, silicato.

\section{Evaluation of sources and extractors of silicon in the soil}

\begin{abstract}
The objective of this work was to evaluate silicon extractors and sources in the culture of the rice in a Quartzipsamment soil in a greenhouse. The experiment was completely randomized as a factorial design (26x7), comprising 25 silicon sources with $250 \mathrm{~kg} \mathrm{ha}^{-1}$ of Si applied, and the control, as well as 7 silicon extractors in the soil. Additional treatments with 125,375 and $500 \mathrm{~kg} \mathrm{ha}^{-1}$ of Si were applied with wollastonite. Ninety days after sowing, the yielded dry matter of aerial parts and the soil and plant tissue $\mathrm{Si}$ content were determined. The source that provided higher $\mathrm{Si}$ absorption to the plants of rice was gel silicon, and the source that provided lower absorption was the MB-4. The extractors presented increased linear content of $\mathrm{Si}$ in the soil with the increment of doses of wollastonite. Among treatments, the high $\mathrm{Si}$ extraction ocurred with the acetic acid, and the calcium chloride went the extractor with better correlation. Ammonium carbonate and ammonium acetate presented near correlations to calcium chloride and had a larger distribution of the points, which better discriminated variations among the Si sources.
\end{abstract}

Index terms: Oryza sativa, slag, metallurgical aggregate, silicate.

\section{Introdução}

O silício ( $\mathrm{Si}$ ) ainda não foi considerado como elemento essencial para os vegetais, porque a sua função ainda não foi bem esclarecida (Epstein, 1999); porém, a absorção de Si traz benefícios, tais como: aumento da tolerância ao ataque de doenças e pragas, diminuição da transpiração, melhora da arquitetura da planta ao tornar as folhas mais eretas e conseqüente melhora da taxa fotossintética (Deren et al., 1994).

As gramíneas são consideradas plantas acumuladoras de $\mathrm{Si}$, assim, a adubação com Si tem aumentado e sustentado a produção de matéria verde e de grãos em espécies como arroz, cana-de-açúcar, sorgo, milheto, aveia, grama 'Kikuyu', grama 'Bermuda' (Elawad \& Green, 1979; Korndörfer \& Lepsch, 2001). Em arroz cultivado em várzea, Korndörfer et al. (2001) observaram aumento médio de produção de grãos de $1.007 \mathrm{~kg} \mathrm{ha}^{-1}$ nos tratamentos com $\mathrm{Si}$, aplicado na forma de silicato de cálcio.

Apesar de o sílicio ser um dos elementos mais abundantes da crosta terrestre e presente em consideráveis quantidades na maioria dos solos, várias classes de solos, principalmente os localizados no 
Cerrado, são pobres em Si solúvel nos horizontes superiores (Raij \& Camargo, 1973). Nessas condições, provavelmente, pode-se esperar resposta para aplicação de Si em forma de fertilizantes, principalmente em plantas acumuladoras de $\mathrm{Si}$, como é o caso da maioria das gramíneas.

Para suprir a necessidade de $\mathrm{Si}$, resíduos de plantas são, em alguns casos, usados como fontes de Si (casca de arroz e bagaço de cana). Além de serem fontes de liberação lenta de $\mathrm{Si}$, apresentam usos mais nobres como a geração de vapor, no entanto são insuficientes para atender à demanda por Si na agricultura. Todavia existem subprodutos da indústria do aço e do ferro gusa, que são as escórias de siderurgia ricas em $\mathrm{Si}$, que poderiam atender essa demanda. As altas temperaturas utilizadas nos processos siderúrgicos liberam o Si de estados cristalinos, presentes no mineral e no fundente, a formas reativas e, consequientemente, mais solúveis (Coelho, 1998).

As principais características de uma fonte de Si para fins de uso na agricultura são: alto conteúdo de Si solúvel, propriedades físicas adequadas, facilidade para a aplicação mecanizada, pronta disponibilidade para as plantas, baixo custo, relações e quantidades de cálcio (Ca) e magnésio $(\mathrm{Mg})$ equilibradas e ausência de metais pesados. Muitas escórias de siderurgia possuem tais características, e algumas delas são fontes promissoras de Si disponível (Korndörfer et al., 2003).

Sumida (1992) cita que um método valioso para diagnosticar a capacidade de suprimento de $\mathrm{Si}$, para solos cultivados com arroz, seria aquele que mede simultaneamente a adsorção e dissolução de $\mathrm{Si}$ em vários tipos de solo com diferentes históricos de aplicação de fertilizantes, e que promove elevada correlação com o $\mathrm{Si}$ contido na palha do arroz. Assim, para se conhecer a necessidade de fertilização com Si, é necessário desenvolver métodos eficientes de análise de Si disponível no solo, na planta e nos fertilizantes (Barbosa Filho et al., 2000).

Imaizumi \& Yoshida (1958) usaram $\mathrm{HCl}$, oxalato de amônio pH 3, $\mathrm{Na}_{2} \mathrm{CO}_{3}$ a $2 \%$, água saturada com $\mathrm{CO}_{2}$, $\mathrm{H}_{2} \mathrm{SO}_{4} 0,002 \mathrm{~N}$ e acetato de amônio $\mathrm{pH} 4$ como extratores de Si no solo e compararam a quantidade de Si absorvida pela planta de arroz com a quantidade de Si extraída dos solos. Os autores concluíram que o Si extraído por ácido diluído teve a melhor correlação com o Si absorvido pelas plantas e, ainda, que o Si solúvel em meio alcalino não refletiu a capacidade do solo em suprir Si para as plantas. Posteriormente, observaram que o Si no solo foi mais solúvel em ácido do que em soluções neutras e que a extração de Si dos solos, por vários reagentes testados, ocorreu na seguinte ordem: oxalato $>$ citrato $>$ tartarato $>$ acetato $>$ cloreto. Disso concluíram que a dissolução do Si no solo aumenta em consequiência da quelatação dos óxidos de $\mathrm{Fe}$ e $\mathrm{Al}$, que funcionam como fixadores de silicatos no solo.

Os níveis críticos de Si no solo, em relação a algumas espécies de plantas, estão sendo atualmente estabelecidos no Brasil, usando-se como extratores de Si do solo o ácido acético e o cloreto de cálcio (Korndörfer et al., 1999, 2001), no entanto, ainda não está definido qual o melhor extrator a ser usado. O ácido acético superestima o teor de $\mathrm{Si}$ nos solos, principalmente nos corrigidos com calcário e naqueles que receberam a aplicação de fontes ricas em aluminossilicatos como as escórias de alto-forno (Pereira et al., 2004). O cloreto de cálcio apresenta baixo coeficiente de determinação, pois a menor concentração de $\mathrm{Si}$ na solução pode acarretar erros de leitura e determinação do Si (Korndörfer et al., 1999). Assim, em razão da crescente demanda pelo uso do $\mathrm{Si}$, há necessidade de se investigar e identificar os extratores mais promissores e que apresentem alto potencial para determinação do Si disponível no solo.

O objetivo deste trabalho foi avaliar vários materiais ricos em $\mathrm{Si}$, quanto à sua capacidade de fornecimento às plantas, e avaliar extratores de $\mathrm{Si}$ do solo e sua correlação com o Si na matéria seca de plantas de arroz.

\section{Material e Métodos}

O trabalho foi realizado com a cultura do arroz, de dezembro de 2004 a abril de 2005, em casa de vegetação, no Centro de Ciências Agrárias e Biológicas, Campus de Jataí, da Universidade Federal de Goiás. Utilizaram-se vasos com $5 \mathrm{~kg}$ de Neossolo Quartzarênico órtico típico, com as seguintes características: $\mathrm{pH}$ (água) 5,$6 ; 26,5 \mathrm{mg} \mathrm{dm}^{-3} \mathrm{de}$ $\mathrm{P}$ (extraído por $\mathrm{H}_{2} \mathrm{SO}_{4} 0,025$ mol $_{\mathrm{c}} \mathrm{dm}^{-3}+\mathrm{HCl} 0,05 \mathrm{~mol}_{\mathrm{c}} \mathrm{dm}^{-3}$ ); $0,8 \mathrm{mg} \mathrm{dm}^{-3} \mathrm{de} \mathrm{Si}$ (extraído por $\mathrm{CaCl}_{2}$ ); $0,2 \mathrm{cmol}_{\mathrm{c}} \mathrm{dm}^{-3} \mathrm{de}$ $\mathrm{Al} ; 0,7 \mathrm{cmol}_{\mathrm{c}} \mathrm{dm}^{-3}$ de $\mathrm{Ca} ; 0,4 \mathrm{cmol}_{\mathrm{c}} \mathrm{dm}^{-3} \mathrm{de} \mathrm{Mg}$; $0,04 \mathrm{cmol}_{\mathrm{c}} \mathrm{dm}^{-3} \mathrm{de} \mathrm{K} ; 0,9 \mathrm{cmol}_{\mathrm{c}} \mathrm{dm}^{-3} \mathrm{de} \mathrm{H}+\mathrm{Al} ; 0,9 \mathrm{~g} \mathrm{~kg}^{-1}$ de matéria orgânica; $945,7 \mathrm{~g} \mathrm{~kg}^{-1}$ de areia; $10,6 \mathrm{~g} \mathrm{~kg}^{-1}$ de silte; $43,7 \mathrm{~g} \mathrm{~kg}^{-1}$ de argila. O solo foi selecionado por possuir baixo teor de Si solúvel em cloreto de cálcio, determinado pelo método de Kilmer (1965). 
Foi utilizado o delineamento experimental inteiramente casualizado, em esquema fatorial $26 \times 7$, com 25 fontes de Si e uma testemunha, 7 extratores de $\mathrm{Si}$ do solo e 4 repetições. Os materiais foram selecionados e caracterizados quanto ao teor de $\mathrm{Si}$ total, $\mathrm{Ca}, \mathrm{Mg}$ e poder de neutralização (PN) (Tabela 1).

A dose de $\mathrm{Si}$ aplicada aos tratamentos foi de $250 \mathrm{~kg} \mathrm{ha}^{-1}$ (Tabela 1). Em cada tratamento foram adicionados $\mathrm{CaCO}_{3}$ e $\mathrm{MgCO}_{3}$ para balancear os valores de $\mathrm{pH}, \mathrm{Ca}$ e $\mathrm{Mg}$. Tratamentos adicionais com doses de 125,375 e $500 \mathrm{~kg} \mathrm{ha}^{-1}$ de $\mathrm{Si}$ foram adicionados ao experimento pelo padrão wollastonita, com o objetivo de se obterem as curvas de absorção de Si pelas plantas de arroz. Em seguida, o solo foi umedecido a cerca de $70 \%$ da capacidade de campo, e ficou em incubação por aproximadamente 40 dias. Depois deste período, foi realizado o plantio da cultura do arroz (Oryza sativa L.), variedade Biguá, fornecida pela Embrapa indicado para o ecossistema de várzea. Para suprir as necessidades nutricionais das plantas, foram aplicados, semanalmente,
$100 \mathrm{~mL}$ de solução nutritiva com, $0,67 \mathrm{~g} \mathrm{dm}^{-3} \mathrm{de} \mathrm{N}$; $0,5 \mathrm{~g} \mathrm{dm}^{-3}$ de $\mathrm{P} ; 0,24 \mathrm{~g} \mathrm{dm}^{-3}$ de $\mathrm{S} ; 0,45 \mathrm{~g} \mathrm{dm}^{-3}$ de K; $0,50 \mathrm{~g} \mathrm{dm}^{-3}$ de B; $0,54 \mathrm{~g} \mathrm{dm}^{-3}$ de Mn; $0,09 \mathrm{~g} \mathrm{dm}^{-3}$ de $\mathrm{Zn}$; $0,02 \mathrm{~g} \mathrm{dm}^{-3} \mathrm{de} \mathrm{Cu} ; 0,02 \mathrm{~g} \mathrm{dm}^{-3} \mathrm{de} \mathrm{Mo,} \mathrm{e} 4 \mathrm{~g} \mathrm{dm}^{-3} \mathrm{deFe}$.

A partir do surgimento da terceira folha, os vasos foram inundados com uma lâmina de água de aproximadamente $1 \mathrm{~cm}$, quando então se realizou o desbaste, tendo-se deixado cinco plantas por vaso. Aos 90 dias depois da emergência, foi realizada a colheita da parte aérea das plantas. Em seguida, essa parte foi levada à secagem a $60^{\circ} \mathrm{C}$ até atingir peso constante, pesada para determinação da matéria seca da parte aérea (MSPA), moída em moinho do tipo Wiley e analisada quanto ao teor de silício (Elliott \& Snyder, 1991).

Para avaliar a quantidade de Si do solo, disponibilizado para as plantas de arroz, foram estudados sete extratores: extração em água $-8 \mathrm{~g}$ de solo com $80 \mathrm{~cm}^{3}$ de água destilada foram agitados, por 1 hora; extração em ácido acético $0,5 \mathrm{~mol} \mathrm{dm}^{-3}-8 \mathrm{~g}$ de solo foram agitados com $80 \mathrm{~cm}^{3}$ de uma solução de ácido acético $0,5 \mathrm{~mol} \mathrm{dm}^{-3}$,

Tabela 1. Características químicas das fontes de silício e quantidades aplicadas nos tratamentos.

\begin{tabular}{|c|c|c|c|c|c|c|c|}
\hline \multirow[t]{2}{*}{ Fonte de silício } & \multirow{2}{*}{$\begin{array}{l}\text { Si total } \\
\left(\mathrm{g} \mathrm{kg}^{-1}\right)\end{array}$} & \multicolumn{2}{|c|}{ Fornecido pelo silicato } & \multirow{2}{*}{$\begin{array}{l}\text { PN calculado } \\
\left(\% \mathrm{E} . \mathrm{CaCO}_{3}\right)^{(1)}\end{array}$} & \multicolumn{3}{|c|}{ Dose por vaso $^{(2)}$} \\
\hline & & ---------( $\left(\mathrm{kg} \mathrm{ha}^{-1}\right)$--------- & $\begin{array}{c}\mathrm{Mg} \\
-----\end{array}$ & & Silicato & $\begin{array}{l}\mathrm{CaCO}_{3} \\
\text { por vas }\end{array}$ & $\mathrm{MgCO}_{3}$ \\
\hline Testemunha & - & 0,0 & 0,0 & 218,3 & 0,00 & 13,37 & 2,50 \\
\hline Wollastonita 250 & 234,6 & 323,0 & 1,2 & 76,4 & 2,66 & 11,36 & 2,49 \\
\hline Silifertil AF & 179,1 & 300,5 & 63,0 & 72,6 & 3,49 & 11,49 & 1,95 \\
\hline CSN AF & 155,8 & 487,5 & 50,4 & 89,1 & 4,01 & 10,32 & 2,06 \\
\hline Açominas AF & 134,0 & 373,1 & 70,5 & 65,7 & 4,66 & 11,04 & 1,88 \\
\hline Usiminas AF & 160,0 & 247,8 & 41,8 & 50,8 & 3,91 & 11,83 & 2,14 \\
\hline Pitangui AF & 165,0 & 251,1 & 11,5 & 44,7 & 3,79 & 11,80 & 2,40 \\
\hline Acesita I AF & 200,0 & 194,6 & 8,0 & 41,7 & 3,13 & 12,16 & 2,43 \\
\hline Acesita II AF & 200,0 & 194,6 & 8,0 & 41,7 & 3,13 & 12,16 & 2,43 \\
\hline Silifertil LD & 57,3 & 1276,3 & 190,4 & 91,3 & 10,91 & 5,39 & 0,84 \\
\hline CSN LD & 50,9 & 988,9 & 224,3 & 69,3 & 12,28 & 7,19 & 0,54 \\
\hline Acesita LD I & 47,1 & 2140,1 & 184,3 & 115,3 & 13,28 & 0,00 & 0,89 \\
\hline Açominas LD & 52,2 & 945,0 & 81,9 & 56,5 & 11,97 & 7,47 & 1,79 \\
\hline Acesita LD II & 50,0 & 932,1 & 228,0 & 65,6 & 12,50 & 7,55 & 0,51 \\
\hline Acesita LD III & 64,0 & 929,1 & 285,9 & 89,9 & 9,77 & 7,57 & 0,00 \\
\hline Acesita B920 & 100,0 & 632,1 & 165,0 & 90,6 & 6,25 & 9,42 & 1,06 \\
\hline Escória de fósforo & 215,2 & 361,0 & 4,8 & 79,6 & 2,90 & 11,11 & 2,46 \\
\hline Escória de aço inox & 108,4 & 604,8 & 130,5 & 89,1 & 5,77 & 9,59 & 1,36 \\
\hline Belgo (siderme) & 73,9 & 622,0 & 255,3 & 77,2 & 8,46 & 9,48 & 0,27 \\
\hline $\mathrm{MB}-4$ & 199,9 & 62,6 & 80,9 & 39,3 & 3,13 & 12,98 & 1,79 \\
\hline Microton pó & 263,0 & 5,7 & 10,3 & 6,0 & 2,38 & 13,34 & 2,41 \\
\hline Serpentinito & 170,0 & 24,2 & 249,7 & 74,3 & 3,68 & 13,22 & 0,32 \\
\hline Xisto & 247,3 & 14,7 & 9,7 & 7,6 & 2,53 & 13,28 & 2,42 \\
\hline Ácido monosilícico & - & - & - & 218,3 & - & 13,37 & 2,50 \\
\hline Silicato de sódio & - & - & - & 218,3 & - & 13,37 & 2,50 \\
\hline Sílica gel & - & - & - & 218,3 & - & 13,37 & 2,50 \\
\hline Wollastonita 125 & 234,6 & 161,5 & 0,6 & 76,4 & 1,33 & 12,36 & 2,50 \\
\hline Wollastonita 375 & 234,6 & 484,5 & 1,8 & 76,4 & 4,00 & 10,35 & 2,49 \\
\hline Wollastonita 500 & 234,6 & 646,0 & 2,4 & 76,4 & 5,33 & 9,34 & 2,48 \\
\hline
\end{tabular}

(1)\%E. $\mathrm{CaCO}_{3}$, porcentual equivalente em $\mathrm{CaCO}_{3}$ de $100 \mathrm{~g}$ do produto. ${ }^{(2)}$ Dose de $\mathrm{CaCO}_{3}$ e $\mathrm{MgCO}_{3}$ para balancear os teores de Ca e $\mathrm{Mg}$ aplicados. 
por 1 hora; extração em cloreto de cálcio $0,01 \mathrm{~mol} \mathrm{dm}^{-3}-$ $8 \mathrm{~g}$ de solo foram agitados com $80 \mathrm{~cm}^{3}$ de uma solução de $\mathrm{CaCl}_{2}$ 0,01 mol dm${ }^{-3}$, por 1 hora; extração em carbonato de sódio $10,6 \mathrm{~g} \mathrm{dm}^{-3}-8 \mathrm{~g}$ de solo foram agitados com $80 \mathrm{~cm}^{3}$ de uma solução de $\mathrm{Na}_{2} \mathrm{CO}_{3} 10,6 \mathrm{~g}$ $\mathrm{dm}^{-3}$, por 1 hora; extração em carbonato de sódio + nitrato de amônio $\left(10 \mathrm{~g} \mathrm{dm}^{-3}+16 \mathrm{~g} \mathrm{dm}^{-3}\right)-8 \mathrm{~g}$ de solo foram agitados com $80 \mathrm{~cm}^{3}$ de uma solução de $\mathrm{Na}_{2} \mathrm{CO}_{3}$ $10 \mathrm{~g} \mathrm{dm}^{-3}+\mathrm{NH}_{4} \mathrm{NO}_{3} 16 \mathrm{~g} \mathrm{dm}^{-3}$, por 1 hora; extração em carbonato de amônio 9,6 $\mathrm{g} \mathrm{dm}^{-3}-8 \mathrm{~g}$ de solo foram agitados com $80 \mathrm{~cm}^{3}$ de uma solução de $\left(\mathrm{NH}_{4}\right)_{2} \mathrm{CO}_{3}$ a $9,6 \mathrm{~g} \mathrm{dm}^{-3}$, por 1 hora; extração em acetato de amônio $38,5 \mathrm{~g} \mathrm{dm}^{-3}-8 \mathrm{~g}$ de solo foram agitados com $80 \mathrm{~cm}^{3} \mathrm{de}$ uma solução de $38,5 \mathrm{~g} \mathrm{dm}^{-3}$, por 1 hora.

Após a agitação, as soluções ficaram em repouso por um dia para a decantação das argilas suspensas e posterior filtragem com papel tipo faixa-azul. Uma alíquota de $10 \mathrm{~cm}^{3}$ foi retirada do extrato (filtrado/decantado) de cada amostra e colocado em um bequer de $50 \mathrm{~cm}^{3}$.

De acordo com Korndörfer et al. (2004), deve-se acrescentar ao extrato $1 \mathrm{~cm}^{3}$ da solução sulfo-molíbdica, para a formação do complexo BETA-molibdosilicato, de coloração amarela, que ocorre depois de 5 min entre pH 1,4 e 2; portanto, em alguns extratores houve a necessidade de redução do $\mathrm{pH}$, antes da aplicação do molibdato de amônio, assim, para a extração com carbonato de sódio, carbonato de sódio + nitrato de amônio, e carbonato de amônio, aplicou-se $1,5 \mathrm{~cm}^{3}$ de ácido clorídrico $\left(1 \mathrm{~mol} \mathrm{dm}^{-3}\right) \mathrm{em} 10 \mathrm{~cm}^{3}$ do extrato, e para a extração com acetato de amônio foram necessários $3 \mathrm{~cm}^{3}$ de ácido clorídrico $\left(1 \mathrm{~mol} \mathrm{dm}^{-3}\right) \mathrm{em}$ $10 \mathrm{~cm}^{3}$ do extrato.

Para a obtenção da curva padrão (uma curva para cada extrator), foi acrescentada água destilada em volume igual ao do ácido acrescentado para cada extrator. Decorridos 10 min da aplicação do molibdato, acrescentaram-se $2 \mathrm{~cm}^{3}$ da solução de ácido tartárico a $200 \mathrm{~g} \mathrm{dm}^{-3}$ utilizado para complexar o P da solução.

Depois de $5 \mathrm{~min}$, adicionaram-se $10 \mathrm{~cm}^{3}$ da solução de ácido ascórbico a $3 \mathrm{~g} \mathrm{dm}^{-3}$, para que a quantificação do silício fosse realizada pela redução do complexo $\beta$-molibdossilicato amarelo a azul-de-molibdênio; depois de 1 hora, foi feita a leitura em espectrofotômetro a $660 \mathrm{~nm}$ (Kilmer, 1965).

Os resultados foram submetidos à análise de variância pelo teste $\mathrm{F}$, e as médias foram comparadas pelo teste de Tukey a 5\% de probabilidade. Na análise dos efeitos das doses de wollastonita, foi empregada a regressão polinomial, tendo-se aplicado a equação obtida com o acúmulo de Si da parte aérea, em função das doses de wollastonita, e também com o Si determinado pelos extratores.

A extração de Si pelo arroz foi correlacionada com o Si extraído do solo pelos diferentes extratores, tendo-se obtido as curvas de correlação e o coeficiente de determinação $\left(R^{2}\right)$ entre o silício extraído pelo arroz e os diferentes extratores de silício do solo.

\section{Resultados e Discussão}

Tanto o teor de Si na parte aérea, quanto a quantidade de Si extraído pelas plantas de arroz, por vaso, apresentaram resposta linear $\mathrm{y}=0,024 \mathrm{x}+16,19$ $\left(R^{2}=0,92, p<0,01\right)$ e $y=0,0007 x+0,42\left(R^{2}=0,99\right.$, $\mathrm{p}<0,01)$, respectivamente, em conseqüência das quantidades crescentes de wallostonita aplicadas ao solo.

No solo, o teor de Si aumentou de forma linear com o incremento das doses de wollastonita, independentemente do extrator utilizado (Figura 1). Isto demonstra que todos os extratores foram eficientes na extração de $\mathrm{Si}$, para discriminar as quantidades crescentes aplicadas, mas, conforme Pereira et al. (2004), isso não serve de parâmetro para se definir o melhor extrator de $\mathrm{Si}$, mas traz informações da exatidão.

O ácido acético extraiu os maiores teores de $\mathrm{Si}$ (entre $20 \mathrm{e}^{2} 3 \mathrm{mg} \mathrm{kg}^{-1}$ ) da wollastonita aplicada ao solo, enquanto o $\mathrm{CaCl}_{2}$ foi o que apresentou a menor extração (teores entre 1,2 e 2,3 $\mathrm{mg} \mathrm{kg}^{-1}$ ). Essa amplitude influencia a exatidão da análise, pois a faixa estreita de extração do $\mathrm{CaCl}_{2}$ pode promover erros de análises. Os demais extratores apresentaram extração na faixa de 2 a $10 \mathrm{mg}$ de Si por quilograma de solo, e apresentaram amplitude intermediária entre o $\mathrm{CaCl}_{2}$ e o ácido acético (Figura 1).

Não houve diferença na produção de matéria seca do arroz em consequiência das fontes de silício utilizadas (Tabela 2). O teor de Si na matéria seca e a extração de silício foram semelhantes à exceção nos tratamentos sílica gel e MB-4. O primeiro foi a fonte que mais liberou Si para as plantas de arroz, o segundo foi a fonte que menos liberou Si. Resultados semelhantes foram obtidos por Pereira et al. (2004).

De forma geral, assim como ocorreu com as doses de wollastonita, pode-se observar que entre os extratores, 
o ácido acético foi o que mais extraiu Si do solo, enquanto o cloreto de cálcio apresentou a menor extração (Tabela 3). A sílica gel foi a fonte que liberou maior quantidade de Si para as diferentes soluções extratoras,
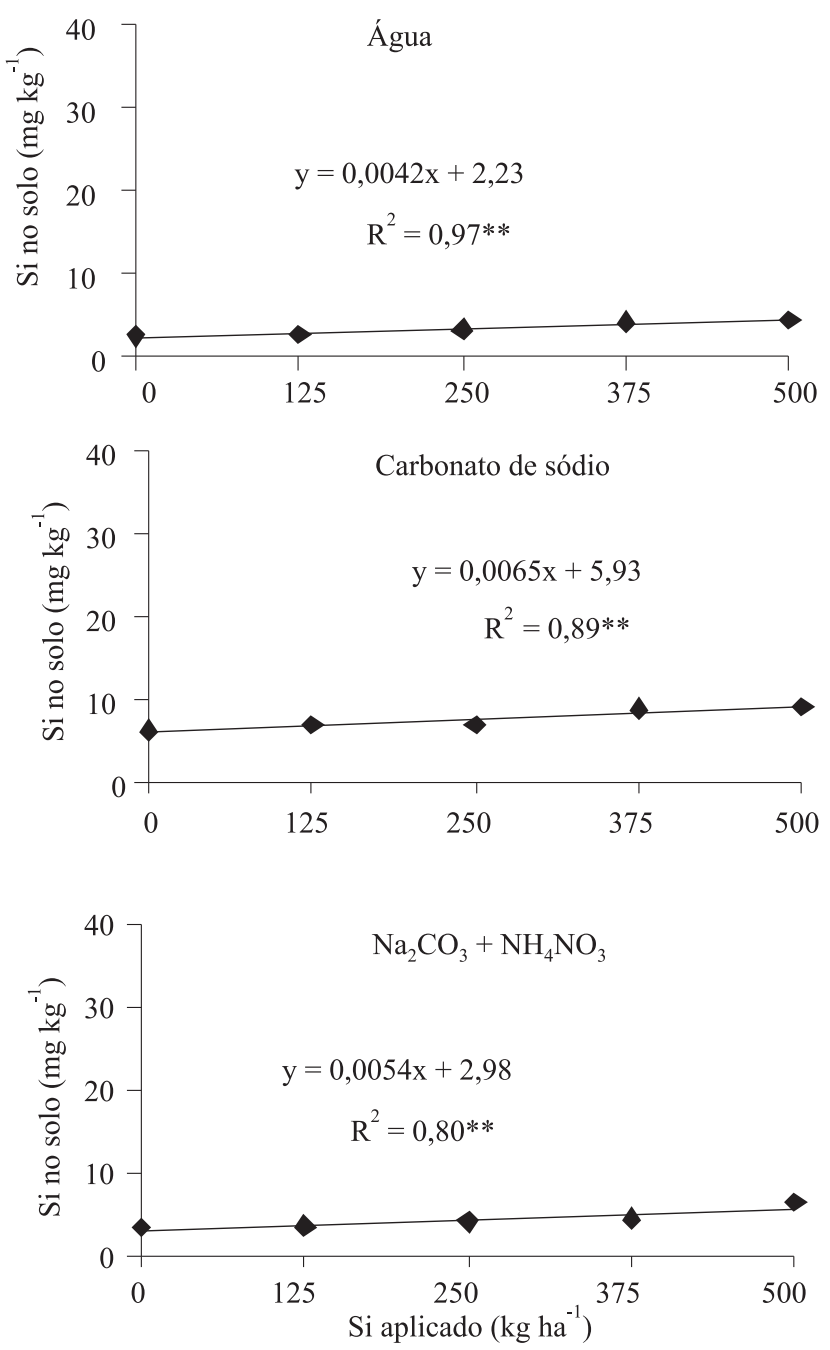

exceto o ácido acético, para o qual a escória de altoforno Açominas AF liberou a maior quantidade de Si.

$\mathrm{Na}$ análise dos teores de Si extraído em água, não houve diferença entre a sílica gel e os tratamentos com
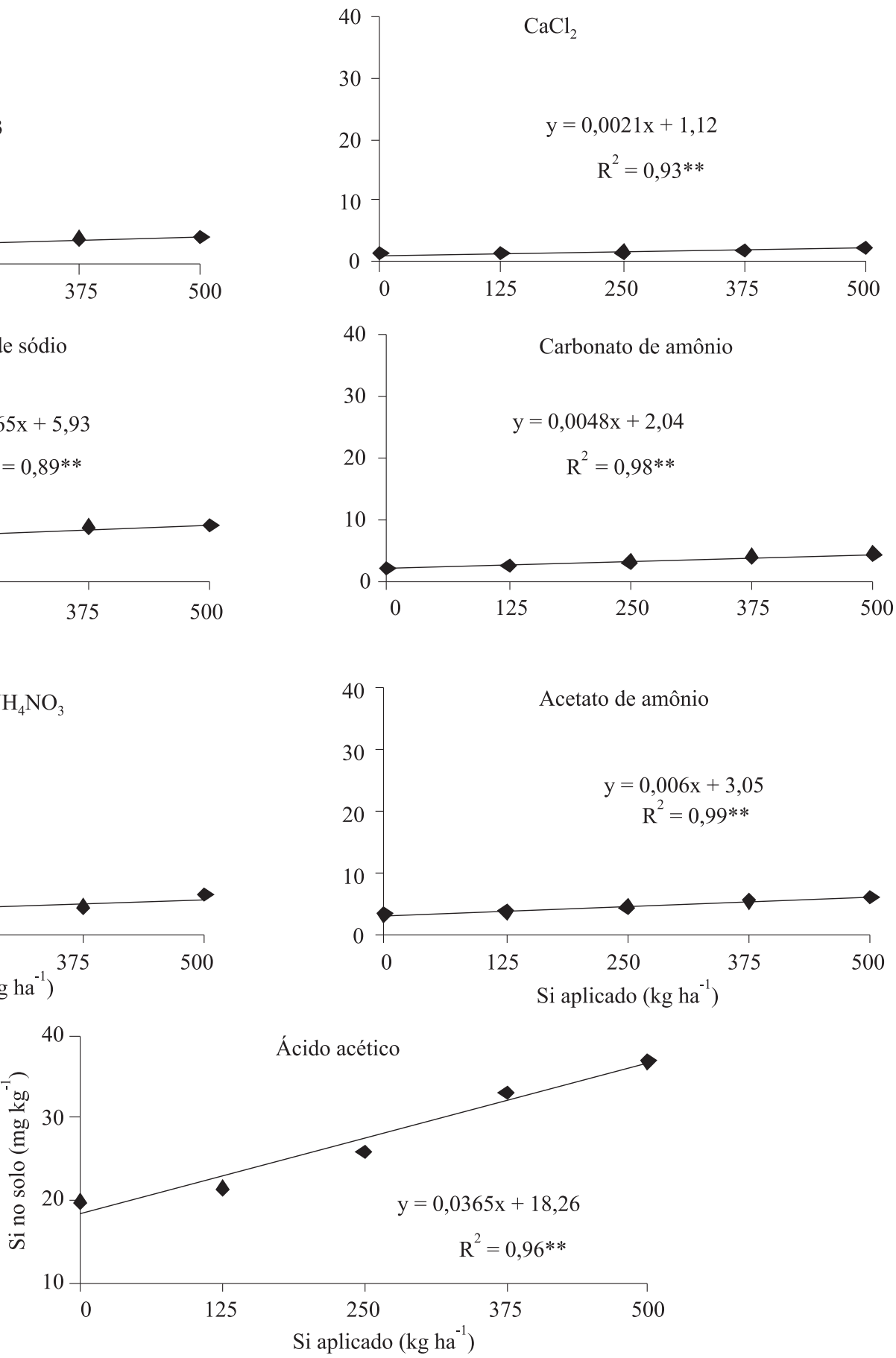

Figura 1. Teor de silício no solo, determinado por diferentes extratores, em função de doses crescentes de Wollostonita. 
as escórias de alto-forno: Açominas AF, Silifertil AF e Pitangui AF que, em geral, são fontes com baixa capacidade de liberar Si. Este fato indica a pouca eficiência da água como extratora de Si no solo.

$\mathrm{O}$ ácido acético foi o extrator que mais extraiu Si das diferentes fontes, em que as escórias de alto-forno da CSN AF, Açominas AF e Acesita AF II apresentaram os maiores teores, tendo diferido das demais fontes. Contudo, as fontes Si de alto-forno não são eficientes no fornecimento de Si para as plantas (Pereira et al., 2003). Esse fato reduz a confiabilidade na mensuração com ácido acético, que consegue extrair Si em grandes quantidades de fontes de baixa solubilidade, se comparado aos teores extraídos de fontes que apresentam maior solubilidade. As escórias de alto-forno são constituídas em sua maior parte de aluminossilicatos de cálcio sob a forma vítrea (Battagin \& Esper, 1987). O silício ligado ao alumínio é mais solúvel em meio ácido, fazendo com que estas fontes liberem mais silício quando se usa um extrator ácido.

Tabela 2. Massa de matéria seca, teor de silício na parte aérea e extração de silício pelas plantas de $\operatorname{arroz}^{(1)}$.

\begin{tabular}{|c|c|c|c|}
\hline Tratamento & $\begin{array}{l}\text { Produção de } \\
\text { matéria seca } \\
\left(\mathrm{g}^{-1} \text { vaso }^{-1}\right)\end{array}$ & $\begin{array}{l}\text { Teor de Si na } \\
\text { matéria seca } \\
\quad\left(\mathrm{g} \mathrm{kg}^{-1}\right)\end{array}$ & 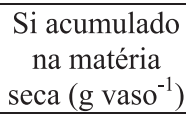 \\
\hline Testemunha & $24,09 \mathrm{a}$ & $17,65 \mathrm{bf}$ & $4,25 \mathrm{df}$ \\
\hline Wollastonita 250 & $27,73 a$ & $18,41 \mathrm{be}$ & $5,10 \mathrm{cf}$ \\
\hline Silifertil AF & $28,70 \mathrm{a}$ & $17,65 \mathrm{bf}$ & $5,06 \mathrm{cf}$ \\
\hline CSN AF & $26,87 \mathrm{a}$ & $14,39 \mathrm{ef}$ & $3,87 \mathrm{ef}$ \\
\hline Açominas AF & $29,66 a$ & $15,85 \mathrm{cf}$ & $4,70 \mathrm{df}$ \\
\hline Usiminas AF & $27,48 \mathrm{a}$ & $17,94 \mathrm{bf}$ & $4,93 \mathrm{cf}$ \\
\hline Pitangui AF & $27,20 \mathrm{a}$ & $17,01 \mathrm{bf}$ & $4,63 \mathrm{df}$ \\
\hline Acesita AF I & $25,15 \mathrm{a}$ & $18,82 \mathrm{bf}$ & $4,73 \mathrm{df}$ \\
\hline Acesita AF II & $27,19 a$ & $16,81 \mathrm{cf}$ & $4,57 \mathrm{df}$ \\
\hline Silifertil LD & $27,89 \mathrm{a}$ & $17,42 \mathrm{bf}$ & $4,86 \mathrm{cf}$ \\
\hline CSN LD & $28,16 a$ & $22,35 b c$ & $6,29 \mathrm{bd}$ \\
\hline Acesita LD I & $31,93 a$ & $22,22 \mathrm{bc}$ & $7,10 \mathrm{bc}$ \\
\hline Açominas LD & $32,11 \mathrm{a}$ & $17,74 \mathrm{bf}$ & $5,70 \mathrm{bf}$ \\
\hline Acesita LD II & $29,23 a$ & $21,67 \mathrm{bd}$ & $6,33 \mathrm{bd}$ \\
\hline Acesita LD III & $26,84 a$ & 20,25 be & $5,44 \mathrm{bf}$ \\
\hline Acesita B920 & $32,73 a$ & $18,21 \mathrm{bf}$ & $5,96 \mathrm{be}$ \\
\hline Escória de fósforo & $24,43 a$ & $22,54 \mathrm{bc}$ & $5,51 \mathrm{bf}$ \\
\hline Escória de aço inox & $25,91 \mathrm{a}$ & $21,49 \mathrm{bd}$ & $5,57 \mathrm{bf}$ \\
\hline Siderme & $31,38 \mathrm{a}$ & $23,87 \mathrm{~b}$ & $7,49 b$ \\
\hline MB-4 & $28,84 a$ & $12,04 \mathrm{f}$ & $3,47 f$ \\
\hline Microton & $26,42 \mathrm{a}$ & $17,51 \mathrm{bf}$ & $4,63 \mathrm{df}$ \\
\hline Serpentinito & $32,56 a$ & $14,98 \mathrm{df}$ & $4,88 \mathrm{cf}$ \\
\hline Xisto & $28,64 a$ & $16,01 \mathrm{cf}$ & $4,59 \mathrm{df}$ \\
\hline Ácido monossilícico & $31,87 \mathrm{a}$ & $17,08 \mathrm{bf}$ & $5,44 \mathrm{bf}$ \\
\hline Silicato de sódio & $23,70 \mathrm{a}$ & $15,89 \mathrm{cf}$ & 3,77 ef \\
\hline Sílica gel & $29,16 a$ & $34,63 \mathrm{a}$ & $10,10 \mathrm{a}$ \\
\hline CV (\%) & 14,98 & 13,39 & 16,00 \\
\hline DMS $(5 \%)$ & 11,49 & 6,88 & 2,30 \\
\hline
\end{tabular}

O cloreto de cálcio foi o extrator que apresentou, quantitativamente, a menor extração de $\mathrm{Si}$, que variou de 0,85 a 3,38 $\mathrm{mg} \mathrm{kg}^{-1}$. Neste extrator, a sílica gel foi a que mais liberou Si para a solução extratora, e diferiu dos demais tratamentos, os quais não diferiram entre si e apresentaram menores teores de $\mathrm{Si}$. O carbonato de sódio apresentou a mesma tendência do cloreto de cálcio, entretanto a extração de Si foi maior e variou de 5,49 a $16,6 \mathrm{mg} \mathrm{kg}^{-1}$.

Com o carbonato de sódio + nitrato de amônio, a sílica gel também apresentou o melhor resultado na liberação de $\mathrm{Si}$, tendo diferido dos demais tratamentos. $\mathrm{O}$ tratamento com Acesita LD III teve resultado intermediário na liberação de $\mathrm{Si}$, enquanto os demais tratamentos não diferiram entre si. Analisando-se ainda, os resultados desse extrator, percebe-se que a maioria das fontes provenientes de alto-forno - Acesita AF II, Açominas AF, CSN AF e Silifertil AF - liberaram pouco Si para a solução.

O carbonato de amônio, assim como o carbonato de sódio + nitrato de amônio, também não extraíram teores elevados de Si nos tratamentos com as fontes de altoforno. As fontes sílica gel, escória de aço inox, Acesita LD I, CSN LD, Silifertil LD e escória de fósforo apresentaram as maiores liberações de Si, não tendo diferido entre si.

$\mathrm{O}$ acetato de amônio foi o extrator que melhor discriminou o Si liberado pelas fontes no solo. A sílica gel e a Acesita LD III apresentaram as maiores liberações de Si diferiram dos demais tratamentos. As fontes Microton, Serpentinito e Açominas AF foram as que menos liberaram $\mathrm{Si}$. As demais fontes apresentaram teores intermediários de Si no solo.

Berthelsen (2000), em um estudo de comparação de métodos de extração de $\mathrm{Si}$, em diferentes classes de solo da Austrália, também encontrou diferentes escalas de magnitudes entre os extratores. Os extratores tendem a atacar o $\mathrm{Si}$ em diferentes componentes da matriz do solo; soluções diluídas salinas, como o $\mathrm{CaCl}_{2}$, mensuram a quantidade de Si disponível na solução do solo, enquanto resultados obtidos com o uso de $\mathrm{NH}_{4} \mathrm{OAc}$ (pH 4) e ácido acético indicam que o Si solubilizado origina-se de polímeros simples.

Berthelsen \& Korndörfer (2005) revisaram vários trabalhos com extratores de Si no solo e verificaram que muitos extratores apresentam excelentes curvas de resposta com o Si obtido pelas plantas, porém, após adições de silicatos nesses solos, alguns extratores passaram a superestimar a disponibilidade de Si para as plantas. 
Analisando-se as correlações entre o teor de Si nas plantas de arroz e o teor de Si no solo, pelos diferentes extratores, verifica-se que o acido acético além de apresentar a correlação mais baixa entre todos os extratores, apresentou resultado contrário ao esperado para um extrator (Figura 2), isso confirma sua capacidade de extrair Si de fontes presentes no solo que são de baixa solubilidade. Barbosa Filho et al. (2001) avaliaram extratores de Si em solos com aplicação e sem aplicação de silicato de cálcio e concluíram que a extração com ácido acético foi a mais eficiente, na avaliação da disponibilidade de $\mathrm{Si}$ nos solos da área agrícola de Everglades na Flórida. Resultados semelhantes também foram obtidos por Korndörfer et al. (1999), mas tais resultados não se confirmam quando se utilizam fontes de diferentes origens.

A água, o carbonato de sódio e o nitrato de sódio + nitrato de amônio tiveram correlações intermediárias, com $\mathrm{R}^{2}$ entre 51 e $64 \%$. Observando-se esses três extratores, percebe-se que os pontos não estão distribuídos uniformemente ao longo da reta que compõe os gráficos, o que indica baixa precisão na ex- tração de Si disponível, em comparação à extração feita pelas plantas de arroz.

O cloreto de cálcio foi o extrator que apresentou a maior correlação entre os extratores testados $\left(\mathrm{R}^{2}=81 \%\right)$, no entanto, em razão de sua baixa extração, não apresentou uma distribuição dos pontos em uma faixa ampla, o que dificulta o estabelecimento de classes de interpretação e, conseqüentemente, aumenta a probabilidade de erros analíticos.

Os extratores acetato de amônio e carbonato de amônio tiveram comportamento semelhante na correlação entre o teor do Si no arroz e o determinado no solo, ambos apresentaram boa dispersão dos pontos, o que indica melhor discriminação entre o menor e o maior valor de $\mathrm{Si}$ encontrado no solo. Pode-se dizer que o carbonato de amônio, por apresentar maior correlação $\left(\mathrm{R}^{2}=78 \%\right)$, teve um melhor desempenho, se comparado ao acetato de amônio cuja correlação foi de 73\%. Nonaka \& Takahashi (1988), trabalharam com o acetato de amônio tamponado a pH 4 e concluíram que esse extrator

Tabela 3. Teor de silício $\left(\mathrm{mg} \mathrm{kg}^{-1}\right)$ no solo, obtido pelos diferentes extratores em função das fontes de silício aplicadas ${ }^{(1)}$.

\begin{tabular}{|c|c|c|c|c|c|c|c|}
\hline Tratamentos & Água & $\begin{array}{l}\text { Ácido } \\
\text { acético }\end{array}$ & $\begin{array}{l}\text { Cloreto } \\
\text { de cálcio }\end{array}$ & $\begin{array}{c}\text { Carbonato } \\
\text { de sódio }\end{array}$ & $\begin{array}{c}\text { Carbonato de sódio + } \\
\text { nitrato de amônio }\end{array}$ & $\begin{array}{l}\text { Carbonato de } \\
\text { amônio }\end{array}$ & $\begin{array}{c}\text { Acetato de } \\
\text { amônio }\end{array}$ \\
\hline Testemunha & $2,39 b$ & $19,83 f$ & $1,25 b$ & $6,13 b$ & $3,37 \mathrm{bc}$ & $2,18 \mathrm{~b}$ & $3,19 \mathrm{~cd}$ \\
\hline Wollastonita 250 & $2,59 \mathrm{ab}$ & $21,44 \mathrm{ef}$ & $1,26 b$ & $6,80 \mathrm{~b}$ & $3,55 \mathrm{bc}$ & $2,54 b$ & $3,63 \mathrm{bd}$ \\
\hline Silifertil AF & $3,23 a b$ & $49,85 \mathrm{df}$ & $1,03 b$ & $5,87 \mathrm{~b}$ & $2,98 \mathrm{c}$ & $2,66 b$ & $3,75 \mathrm{bd}$ \\
\hline CSN AF & $2,63 b$ & $101,49 \mathrm{ac}$ & $1,08 b$ & $6,54 b$ & $3,00 \mathrm{c}$ & $2,60 \mathrm{~b}$ & $3,42 \mathrm{~cd}$ \\
\hline Açominas AF & $3,41 \mathrm{ab}$ & $137,27 \mathrm{a}$ & $0,96 b$ & $5,81 b$ & $3,07 \mathrm{c}$ & $2,07 b$ & $2,96 \mathrm{~d}$ \\
\hline Usiminas AF & $2,90 \mathrm{~b}$ & $61,67 \mathrm{ce}$ & $1,17 b$ & $7,26 b$ & $3,56 \mathrm{bc}$ & $2,64 b$ & $3,42 \mathrm{~cd}$ \\
\hline Pitangui AF & $3,13 \mathrm{ab}$ & $83,46 b d$ & $1,07 \mathrm{~b}$ & $6,76 b$ & $3,93 \mathrm{bc}$ & $2,39 b$ & $3,32 \mathrm{~cd}$ \\
\hline Acesita AF I & $2,53 b$ & $95,15 \mathrm{bc}$ & $1,14 b$ & $5,49 b$ & $3,48 \mathrm{bc}$ & $1,54 b$ & $3,28 \mathrm{~cd}$ \\
\hline Acesita AF II & $2,80 \mathrm{~b}$ & $114,39 \mathrm{ab}$ & $1,12 b$ & $5,72 b$ & $3,22 \mathrm{c}$ & $1,71 b$ & $3,34 \mathrm{~cd}$ \\
\hline Silifertil LD & $3,43 a b$ & 34,87 ef & $1,40 \mathrm{~b}$ & $7,15 b$ & $4,27 \mathrm{bc}$ & $3,41 \mathrm{ab}$ & $5,47 b c$ \\
\hline CSN LD & $3,03 \mathrm{ab}$ & $34,85 \mathrm{ef}$ & $1,73 b$ & $7,75 b$ & $3,45 \mathrm{bc}$ & $3,44 \mathrm{ab}$ & $5,54 b c$ \\
\hline Acesita LD I & $3,53 \mathrm{ab}$ & $32,27 \mathrm{ef}$ & $1,45 b$ & $7,78 b$ & $4,63 \mathrm{bc}$ & $3,50 \mathrm{ab}$ & $5,54 \mathrm{bc}$ \\
\hline Açominas LD & $2,90 \mathrm{~b}$ & $36,46 \mathrm{ef}$ & $1,27 b$ & $7,18 b$ & $4,93 \mathrm{bc}$ & $2,95 b$ & $4,67 \mathrm{bd}$ \\
\hline Acesita LD II & $3,58 \mathrm{ab}$ & $31,27 \mathrm{ef}$ & $1,76 b$ & $8,07 \mathrm{~b}$ & $5,40 \mathrm{bc}$ & $3,01 b$ & $4,88 \mathrm{bd}$ \\
\hline Acesita LD III & $3,64 \mathrm{ab}$ & $32,80 \mathrm{ef}$ & $1,73 b$ & $8,90 \mathrm{~b}$ & $7,02 \mathrm{~b}$ & $2,99 b$ & $5,98 \mathrm{ab}$ \\
\hline Acesita B920 & $2,68 b$ & $22,92 \mathrm{ef}$ & $1,05 b$ & $7,14 b$ & $5,51 \mathrm{bc}$ & $2,61 b$ & $4,28 \mathrm{bd}$ \\
\hline Escória de fósforo & $2,66 b$ & $30,50 \mathrm{ef}$ & $1,33 b$ & $7,17 \mathrm{~b}$ & $3,57 \mathrm{bc}$ & $3,34 \mathrm{ab}$ & $4,74 \mathrm{bd}$ \\
\hline Escória de aço inox & $2,74 b$ & $31,87 \mathrm{ef}$ & $1,31 b$ & $6,54 b$ & $4,53 \mathrm{bc}$ & $3,64 a b$ & $4,12 \mathrm{bd}$ \\
\hline Siderme & $2,62 b$ & $40,46 \mathrm{ef}$ & $1,46 b$ & $6,00 \mathrm{~b}$ & $4,45 \mathrm{bc}$ & $3,19 b$ & $4,61 \mathrm{bd}$ \\
\hline MB-4 & $2,21 b$ & $17,68 f$ & $0,85 b$ & $6,01 b$ & $3,07 \mathrm{c}$ & $2,28 b$ & $3,16 \mathrm{~cd}$ \\
\hline Microton & $3,00 \mathrm{ab}$ & $17,65 f$ & $1,22 b$ & $5,79 b$ & $3,02 \mathrm{c}$ & $1,66 b$ & $3,06 \mathrm{~d}$ \\
\hline Serpentinito & $2,55 b$ & $19,16 \mathrm{f}$ & $1,01 b$ & $6,44 b$ & $4,60 \mathrm{bc}$ & $1,73 b$ & $2,99 d$ \\
\hline Xisto & $2,41 b$ & $20,78 f$ & $1,09 b$ & $5,62 b$ & $3,99 \mathrm{bc}$ & $1,66 b$ & $3,40 \mathrm{~cd}$ \\
\hline Ácido monossilícico & $2,65 b$ & $23,87 \mathrm{ef}$ & $1,48 b$ & $7,48 b$ & $5,45 \mathrm{bc}$ & $2,31 b$ & $4,31 \mathrm{bd}$ \\
\hline Silicato de sódio & $3,70 \mathrm{ab}$ & $25,65 \mathrm{ef}$ & $1,29 b$ & $6,01 b$ & $3,98 \mathrm{bc}$ & $2,17 b$ & $3,91 \mathrm{bd}$ \\
\hline Sílica gel & $5,56 \mathrm{a}$ & $24,31 \mathrm{ef}$ & $3,38 \mathrm{a}$ & $16,60 \mathrm{a}$ & $17,72 \mathrm{a}$ & $5,97 \mathrm{a}$ & $8,29 a$ \\
\hline CV $(\%)$ & 31,33 & 32,84 & 25,41 & 18,22 & 29,74 & 37,33 & 20,77 \\
\hline Dms 5\% & 2,58 & 39,95 & 0,93 & 3,49 & 3,73 & 2,75 & 2,38 \\
\hline
\end{tabular}

${ }^{(1)}$ Médias seguidas por letras iguais, na coluna, não diferem significativamente pelo teste de Tukey, a 5\% de probabilidade. 

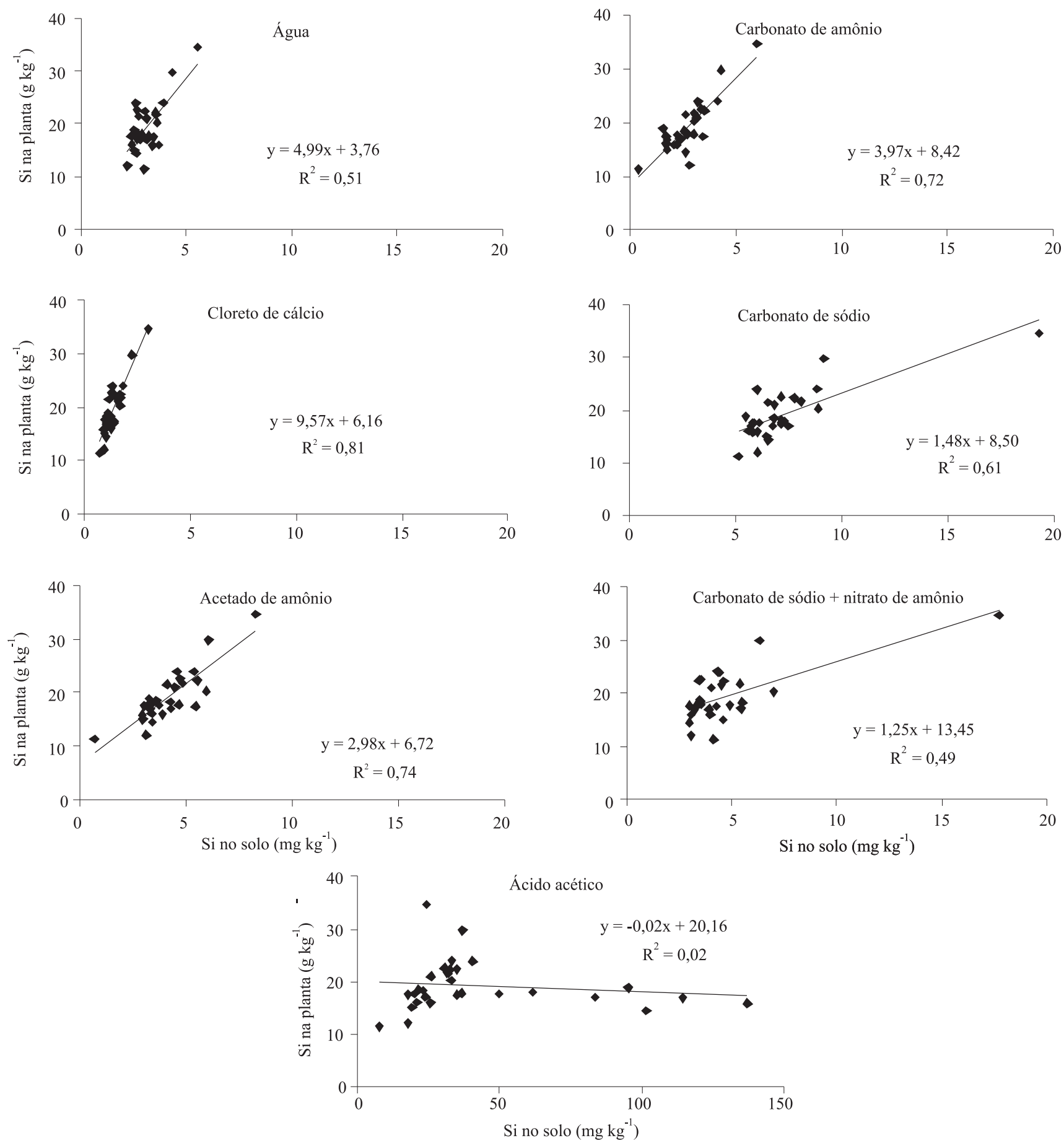

Figura 2. Correlações entre o teor de silício na planta de arroz e no solo, determinado pelos diferentes extratores.

é muito forte para estimar o Si disponível para as plantas. Assim como ocorre com os extratores ácidos, quando se reduz o pH da solução, a extração de formas de Si menos disponíveis devem ocorrer. $\mathrm{O}$ acetato de amônio em $\mathrm{pH}$ próximo de 7 demonstrou-se como o extrator mais confiável.

\section{Conclusões}

1. A sílica gel é a fonte mais eficiente no fornecimento de silício para a cultura do arroz, e a MB-4 a fonte de menor eficiência. 
2. O ácido acético não é um extrator confiável para determinação do silício do solo, principalmente, quando é aplicada uma fonte de silício ao solo.

3. O cloreto de cálcio foi o melhor extrator do silício do solo, apesar de suas limitações pela estreita faixa de determinação.

4. O carbonato de amônio e o acetato de amônio discriminam as variações entre as diferentes fontes de silício e têm potencial para uso na determinação de $\mathrm{Si}$ no solo.

\section{Agradecimentos}

Ao CNPq, pelo suporte financeiro.

\section{Referências}

BARBOSA FILHO, M.P.; SNYDER, G.H.; ELLIOTT, C.L.; DATNOFF, L.E. Evaluation of soil test procedures for determining rice-available silicon. Communications in Soil Science and Plant Analysis, v.32, p.1779-1792, 2001.

BARBOSA FILHO, M.P.; SNYDER, G.H.; PRABHU, A.S.; DATNOFF, L.E.; KORNDORFER, G.H. Importância do silício para a cultura do arroz. Piracicaba: Potafos, 2000. 8p. (Encarte técnico, 89).

BATTAGIN, A.F.; ESPER, M.W. Contribuição ao conhecimento das propriedades do cimento Portland de alto-forno. São Paulo: Associação Brasileira de Cimento Portland, 1987. 91p.

BERTHELSEN, S. An assessment of the silicon status of soil in North Queesland, and the impact of sub-optimal plant available soil silicon on sugarcane production systems. 2000. 261p. Thesis (M.Sc.) - James Cook University, Townsville.

BERTHELSEN, S.; KORNDÖRFER, G.H. Methods for Si analysis in plant, soil and fertilizers. In: SILICON IN AGRICULTURE CONFERENCE, 3., 2005, Uberlândia. Anais. Uberlândia: UFU, 2005. p.85-91.

COELHO, P.E. Da escória ao vidro. Revista Limpeza Pública, v.49, p.36-45, 1998.

DEREN, C.W.; DATNOFF, L.E.; ZINDER, G.H.; MARTÍN, F. Silicon concentration disease response and yield components of rice genotypes grown on flooded organic Histosols. Crop Science, v.34, p.733-737, 1994.

ELAWAD, S.H.; GREEN JUNIOR, V.E. Silicon and the rice plant environment: a review of recent research. Il Riso, v.28, p.235-253, 1979.
ELLIOTT, C.L.; SNYDER, G.H. Autoclave-induced digestion for the colorimetric determination of silicon in rice straw. Journal of Agricultural and Food Chemistry, v.39, p.1118-1119, 1991.

EPSTEIN, E. Silicon. Annual Review of Plant Physiology and Plant Molecular Biology, v.50, p.641-664, 1999.

IMAIZUMI, K.; YOSHIDA, S. Edaphological studies on silicon supplying power of paddy soils. Bulletin of the National Institute of Agricultural Sciences, v.8, p.261-304, 1958.

KILMER, V.J. Silicon. In: BLACK, C.A. (Ed.). Methods of soil analysis: chemical and microbiological properties. Madison: American Society of Agronomy, 1965. v.2, p.959-962. (Agronomy, 9).

KORNDÖRFER, G.H.; COELHO, N.M.; SNYDER, G.H.; MIZUTANI, C.T. Avaliação de métodos de extração de silício para solos cultivados com arroz de sequeiro. Revista Brasileira de Ciência do Solo, v.23, p.101-106, 1999.

KORNDÖRFER, G.H.; LEPSCH, I. Effect of silicon on plant growth and yield. In: DATNOFF, L.E.; KORNDÖRFER, G.H.; SNYDER, G.H. (Ed.). Silicon in agriculture. Amsterdam: Elsevier, 2001. p.133-147.

KORNDÖRFER, G.H.; PEREIRA, H.S.; CAMARGO, M.S. Silicatos de cálcio e magnésio na agricultura. Uberlândia: GPSiICIAG-UFU, 2003. 53p. (Boletim técnico, 1).

KORNDÖRFER, G.H.; PEREIRA, H.S.; NOLA, A. Análise de silício: solo, planta e fertilizante. Uberlândia: GPSi-ICIAG-UFU, 2004. 34p. (Boletim técnico, 2).

KORNDÖRFER, G.H.; SNYDER, G.H.; UCHOA, G.; DATNOFF, L.E. Calibration of soil and plant silicon analysis for rice production. Journal of Plant Nutrition, v.24, p.1071-1084, 2001.

NONAKA, K.; TAKAHASHI, K. A method of measuring available silicates in paddy soil. Japan Agricultural Research Quarterly, v.22, p.91-95, 1988.

PEREIRA, H.S.; KORNDÖRFER, G.H.; MOURA, W.F.; CORREA, G.F. Extratores de silício disponível em escórias e fertilizantes. Revista Brasileira de Ciência do Solo, v.27, p.265274, 2003.

PEREIRA, H.S.; KORNDÖRFER, G.H.; VIDAL, A.A.; CAMARGO, M.S. de. Silicon sources for rice crop. Scientia Agricola, v.61, p.522-528, 2004.

RAIJ, B. van; CAMARGO, O.A. Sílica solúvel em solos. Bragantia, v.32, p.223-236, 1973.

SUMIDA, H. Silicon supplying capacity of paddy soils and characteristics of silicon uptake by rice plants in cool regions in Japan. Bulletin of the Tohoku National Agricultural Experiment Station, v.85, p.1-46, 1992. 